\title{
SECTION 8 - REGULATION OF GROWTH AND DEVELOPMENT
}

\section{5-azacytidine induces lateral branching in Chenopodium rubrum}

\author{
J.T.P. ALBRECHTOVÁ, J. ULLMANN and J. KREKULE \\ Institute of Experimental Botany, Czechoslovak Academy of Sciences, \\ Ke dvoru 15, 16630 Praha 6, Czechoslovakia
}

Biol. Plant. 34 (Suppl.): 569, 1992

5-azacytidine (azaC) is known to prevent methylation of DNA. The effect of azaC was studied in C. rubrum. Plants of various ages (not more than $8 \mathrm{~d}$ ) were either germinated in azaC $\left(10^{-4} \mathrm{M}\right)$ or a droplet of azaC $\left(10^{-4}\right.$ or $\left.10^{-5} \mathrm{M}\right)$ was applied to the plumule. A part of the treated plants was subjected to photoperiodic flower induction (from 1 to 3 cycles depending on the age). AzaC in every treatment changed growth correlations: in general it induced lateral branching and inhibited growth of the stems and leaves. Intensity of these changes depended on the age and on treatments. The effect was less pronounced in induced plants. In some plants germinated in azaC, significant enlargement of apical meristem appeared. AzaC increased flowering to a certain extent in some cases. This was probably due to a decrease in apical dominance.

\section{The comparison of some enzymes from female and male meristem cultures of Actinidia deliciosa (A. Chev.) var. deliciosa}

\section{O. AUXTOVÁ* and B. CHOLVADOVÁ**}

Institute of Chemistry, Slovak Academy of Sciences,

Dúbravská cesta 9, 84238 Bratislava, Czechoslovakia*

Department of Plant Physiology, Comenius University,

Mlynská dolina B-2, 84215 Bratislava, Czechoslovakia**

Biol. Plant. 34 (Suppl.): 569, 1992

Actinidia is a heterooeceious plant. Identification of the sex is possible only after three or four years of cultivation, when plants start flowering for the first time. No differences between female and male plants were found when amounts and extention of singular proteins sites had been compared by observation of the total protein spectra. Six zones of enzymes in the male shoots and five zones in the female were found using $p$-phenylenediamine. Providing zeatin was used for cultivation, male shoots contained five and female four zones with polyphenoloxidase activity. The stabile peroxidase iscenzyme characteristic for male plant material was found in the position between 0.85 and 0.90 Rf. On the other hand, stabile polyphenoloxidase isoenzyme was found in the position of $\mathbf{R f}$ between 0.35 and 0.40 in the material cultivated in the media with $1 \mathrm{mg} \mathrm{l}^{-1}$ of zeatin, while it was found in the position of Rf between 0.85 and 0.90 in the material cultivated in the media with 0.5 $\mathrm{mg} \mathrm{l}^{-1}$ of IBA. These characteristic stabile isoenzymes were not found in the female plants. 


\title{
Effect of some oligosaccharides on the growth of pea and spruce stem segments
}

\author{
O. AUXTOVÁ, D. LIŠKOVÁ, M. KUBAČKOVÁ, Š. KARÁCSONYI and L. BILISICS \\ Institute of Chemistry, Slovak Academy of Sciences, \\ Dúbravská cesta 9,84238 Bratislava, Czechoslovakia
}

Biol. Plant. 34 (Suppl.): 570, 1992

The effect of cytoplasmic acidic oligosaccharides isolated from poplar callus cells and galactoglucomannans (GGM) isolated from poplar wood (Populus monilifera H.) have been tested on the 2,4-D induced growth of pea and spruce stem segments in a concentration range from 0.1 to $75 \mu \mathrm{g} \mathrm{ml}^{-1}$ medium. Cytoplasmic oligosaccharides showed a stimulation effect (maximum $70 \%$ ) on the growth of pea stem segments under the light, an inhibition effect in the case of spruce segments under the light and in the dark as well as inhibition of pea segments growth in the dark. The maximum (75 \%) inhibition of GGM on 2,4-D induced growth of spruce segments was found in the dark.

\section{Benzyladenine inhibits photoperiodic flower induction in the explants of Chenopodium rubrum L. in vitro}

\author{
A. BLAŽKOVÁ, I. MACHÁCKKOVÁ, Z. VONDRÁKOVẢ and J. KREKULE \\ Institute of Experimental Botany, Czechoslovak Academy of Sciences, \\ Ke dvoru 15, 16630 Praha 6, Czechoslovakia
}

Biol. Plant. 34 (Suppl.): 570, 1992

Despite the fact that there is no evidence for direct florigenic activity of cytokinins (CKs), they were demonstrated to be involved in some growth and morphogenetic changes, which are believed to be related to the transition to flowering. The role of CKs in flowering was investigated in SDP Chenopodium rubrum L., ecotype 374. Seedlings or explants were cultivated in vitro using halfstrength Knop's solution, $0.7 \%$ agar and $2 \%$ sucrose with or without 6-benzylaminopurine (BAP) in the concentrations $0.05,0.2,0.4 \mathrm{mg} \mathrm{l}^{-1}$. Plants were induced to flower by one inductive dark period of $13 \mathrm{~h}$. Exogenous BAP application inhibited flowering of photoperiodically induced explants and at the same time stimulated initiation and formation of leaf primordia. This effect was most pronounced with the concentration of BAP $0.05 \mathrm{mg} \mathrm{l}^{-1}$ when BAP was present in the medium during the inductive dark period. Uptake of BAP during $13 \mathrm{~h}$ of inductive darkness and later on was checked using ${ }^{3} \mathrm{H}$-BAP. Segments took up approximately $17.3 \mathrm{ng} \mathrm{BAP}^{-1}$ fresh mass in darkness compared with approximately $33.5 \mathrm{ng} \mathrm{BAP} \mathrm{g}^{-1}$ during the light period. We further studied the effect of BAP application during $13 \mathrm{~h}$ of inductive darkness on endogenous level of zeatin, zeatin riboside, isopentenyladenine and isopentenyladenosine, as measured by ELISA after HPLC separation. At the end of inductive darkness a decrease in the levels of endogenous CKs was observed. The presence of BAP in the medium did not affect this decrease significantly. Thus, the inhibitory effect of BAP on flowering with simultaneous stimulation of initiation and formation of leaf primordia could not be due to its effect on endogenous CKs levels. 


\title{
The level of endogenous cytokinins in lateral cotyledonary buds of pea seedlings during restoring of apical dominance
}

\author{
J. BLAŽKKOVÁ and S. PROCHÁZKA \\ Department of Botany, University of Agriculture, Zemědělská 1,61300 Brmo, Czechoslovakia
}

Biol. Plant. 34 (Suppl.): 571, 1992

The restoring of apical dominance was followed between axillary buds of the etiolated, decapitated 5-d-old pea seedlings deprived of one cotyledon with regard to changes of the endogenous levels of cytokinins in cotyledonary buds during this process. Cytokinins play an important role in the process of restoration of apical dominance between the two axillary buds. The endogenous levels of zeatin (Z), zeatin riboside (ZR), isopentenyladenine (iPA) and isopentenyladenosine (iPAdo) was determined by an immunological method. iPA was by far the most abundant of the four cytokinins in buds. $24 \mathrm{~h}$ after decapitation (in the period of intensive growth of bud) the level of $\mathrm{Z}$ and IPA increased significantly in the released buds. The high level of cytokinins in the buds was caused by cotyledonary bud outgrowth.

\section{Phloem transport of ABA to reproductive sinks in Ricinus communis}

\author{
V. BORKOVEC* and D.A. BAKER** \\ Department of Nuclear Methods, University of Agriculture, \\ Zemédèlská 1, 61300 Brno, Czechoslovakia* \\ Department of Biochemistry and Biological Sciences, Wye College, University of London, \\ Ashford, Kent TN25 5AH, U.K**
}

Biol. Plant. 34 (Suppl.): 571, 1992

Phloem transport of ${ }^{3} \mathrm{H}-\mathrm{ABA}$ and its distribution to the apical part of the plant, fruits and seeds after its application to a leaf blade of Ricinus communis was determined concurrently with RIA of the endogenous levels of (+)-S-ABA in these tissues and organs. ${ }^{3} \mathrm{H}-\mathrm{ABA}$ was readily transported through the phloem towards developing fruits and seeds. The accumulation of ${ }^{3} \mathrm{H}-\mathrm{ABA}$ in these tissues resembled the assimilate distribution pattern indicating that transport from assimilating organs rather than biosynthesis in situ takes place. The endogenous level of ABA in the phloem sap was similar in both vegetative and reproductive plants. The ABA level in the developing endosperm and embryo was indicative of a phloem sap dependent uptake only. A sharp decline in the endogenous level of $\mathrm{ABA}$ in these tissues at the end of maturation is taken to imply that when transport ceases the breakdown of ABA continues and thus decreases its level in these tissues. The experimental data provide evidence that the ABA level in developing fruit and seed parts is a reflection of the ABA level in phloem sap. Whether this high level of ABA regulates the processes of assimilate unloading in the sink tissues as postulated by some authors remains unresolved. 
Biosythesis and phloem translocation of ${ }^{14} \mathrm{C}$-labelled IAA after application of ${ }^{14} \mathrm{C}$ labelled tryptophan to the leaf of Ricinus communis

\author{
V. BORKOVEC ${ }^{*}$, F. DIDEHVAR ${ }^{* *}$ and D.A. BAKER** \\ Department of Nuclear Methods, University of Agriculture, \\ Zemédèlská I, 613 00 Brno, Czechoslovakia* \\ Department of Biochemistry and Biological Sciences, Wye College, University of London, \\ Ashford, Kent TN25 SAH, U.K**
}

Biol. Plant. 34 (Suppl.): 572, 1992

The biosynthesis of ${ }^{14} \mathrm{C}$-IAA from ${ }^{14} \mathrm{C}$-tryptophan applied to abraded leaves of Ricinus communis and its subsequent export through the incisions made in the stem bellow the IAA-fed leaf. Any upward movement of label or downward movement of phloem mobile compounds from leaves above the treated one were restricted by bark ringing the plants. TLC and HPLC analyses of the collected sap indicates that some conversion of ${ }^{14} \mathrm{C}$-tryptophan to ${ }^{14} \mathrm{C}$-IAA occurred. Subsequent GC-MS analysis of the HPLC purified samples of phloem sap (at Long Ashton Research Station) revealed high levels of endogenous IAA transported from the fed leaf. The high ratio of unlabelled/labelled IAA in the phloem sap makes unequivocal confirmation by GC-MS of this biosynthesis of ${ }^{14} \mathrm{C}$-IAA impossible. Localization of ATPase activity at the EM level in the vascular tissues of Ricinus petioles was investigated. An increased density of reaction products was observed in material pre-treated with $10^{-5} \mathrm{~mol} \mathrm{l}^{-1}$ IAA suggesting stimulation of the ATPase activity. The implications of these findings for the long-distance transport of IAA in the vascular system will be presented.

\title{
Transport of calcium and its relationship to the auxin stimulated transport processes in pea epicotyl segments
}

\author{
V. BORKOVEC*. Z. TESAŘOVÁ** and S. PROCHÁZKA** \\ Department of Nuclear Methods, University of Agriculture, \\ Zemédèlská 1, 61300 Brno, Czechoslovakia* \\ Department of Botany and Plant Physiology, University of Agriculture, \\ Zemédélská 1, 61300 Brno, Czechoslovakia**
}

Biol. Plant. 34 (Suppl.): 572, 1992

Transport of ${ }^{45} \mathrm{Ca}$ in etiolated pea epicotyl segments with a different capacity of growth was studied with respect to its role in IAA and PAA stimulated transport processes. The acropetal and basipetal transport of ${ }^{45} \mathrm{Ca}$ was limited to the part of the segment adjacent to the donor agar block and only traces of label moved acropetally and basipetally. IAA/PAA application to the growth inducible part of the segment led to the increased transport of ${ }^{45} \mathrm{Ca}$ to this part of segment. A simultaneous application of $\mathrm{Ca}^{2+}$ and $\mathrm{Co}^{3+}$ reversed the $\mathrm{Co}^{3+}$ stimulated transport of ${ }^{14} \mathrm{C}$-sucrose to the apical part of segments from the apical part of the epicotyl possessing a remaining growth activity. Inhibition of the basipetal ${ }^{3} \mathrm{H}$-IAA transport by simultaneous application of $\mathrm{Co}^{3+}$ suggests that $\mathrm{Co}^{3+}$ could inhibit the endogenous regulation of IAA transport of IAA transport system related to the presence of $\mathrm{Ca}^{2+}$. 


\title{
Axiliary bud growth control by retardants after decapitation of tobacco plants
}

\author{
V. CZAKOVÁ ${ }^{*}$ and M. ZIMA** \\ Tobacco Research Institute, 95134 Báb, Czechoslovakia* \\ Department of Plant Physiology, University of Agriculture, \\ A. Hlinku 2, 94976 Nitra, Czechoslovakia**
}

Biol. Plant. 34 (Suppl.): 573, 1992

Inhibition of axiliary bud growth after the removal of apical dominance following the decapitation of tobacco (Nicotiana tabacum L.) plants has been a serious practical problem. Success of decapitation is connected with the use of retardants for the sucker growth inhibition. Series of growth retardants with different action modes and application methods were tested in field experiments during 1987-1989. From the local - systemic group of preparations the Czechoslovak preparation SYNFLORAN (trifluralin) has shown similar inhibitory effects as flumetralin (PRIME ${ }^{+}$ $250 E C$ preparation) and pendimethalin (preparation STOMP).

\section{Stability of isozyme patterns Est in dependence on ontogenetic leaf stage of grasses}

\author{
K. DOLEŽAL \\ Grassland Research Station, 75654 Zubři, Czechoslovakia
}

Biol. Plant. 34 (Suppl.): 573, 1992

The isozyme system Est was selected for characterization of the parental genotype for tissue cultures (somatic embryogenesis, production of haploid plants) because of its considerable polymorphism in the following materials. But at first the stability of its banding patterns had to be verified. Wu et al. (1984) discusses the fundamental stability of zymograms of grass genotypes. Young leaves and leaves after cutting were taken from plants of Lolium multiflorum cv. Roznovsky and Festulolium cv. Bečva growing in field conditions. Upper and bottom parts of these leaves were crushed in three times more of $0.1 \mathrm{M}$ Tris mercaptoethanol buffer $(\mathrm{pH} 7.2)$ and twice centrifuged (10000 g for $5 \mathrm{~min}$ at $4{ }^{\circ} \mathrm{C}$ ). These samples $(20 \mu \mathrm{l})$ (thickened with sucrose) were applied into $10 \%$ vertical discontinual PAGE gel $(90 \times 80 \times 7 \mathrm{~mm})$. After finishing electrophoresis gels were stained for Est (Vallejos 1983, modified method) and fixed by $50 \%$ glycerol. The banding patterns of individual genotypes were stable and independent on any part and age of leaf. The zymograms were the same both in plants cultivated in vitro and in field conditions. Any change was not observed at banding patterns of following genotypes even in this case. Morover, each of the 30 studied genotypes had individual spectrum, differing from the others. Thus the possibility of using isozymes Est for characterization of genotypes of grasses was proved.

\section{References:}

Vallejos, C.E.: In: Tanksley, D.S., Orton, T.J. (ed.): Isozymes in Plant Genetics and Breeding. Part A. Pp. 469-515. Elsevier, Amsterodam 1983.

Wu, L., Harivandi, A.H., Harding, A.H., Davis, W.B.: Crop Sci. 24: 763-768, 1984. 


\title{
Effect of PAA on adventitious root formation in selected tree species
}

\section{T. DOLEŽELOVÁ and V. PSOTA}

Institute of Systematic and Ecological Biology, Czechoslovak Academy of Sciences, Květmá 6, 6013 65 Brno, Czechoslovakia

Biol. Plant. 34 (Suppl.): 574, 1992

Phenylacetic acid (PAA) is one of the native phytohormones of non-indole character. Its influence on rooting of tree species is little known in practice. In the experiment, its exogenous effect on adventitious root formation was observed. For comparison two other auxin-like growth regulators were applied, native indoleacetic acid (IAA) and synthetic naphthylacetic acid (NAA), whose effects on rooting had been experienced earlier. All the three growth regulators were used at the following concentrations: $10^{-6}, 10^{-5}, 10^{-4}$, and $10^{-3} \mathrm{~mol} \mathrm{dm}^{-3}$. It was found that the effects of PAA were similar to those of IAA. At higher PAA and IAA concentrations $\left(10^{-5}\right.$ and $\left.10^{-4} \mathrm{~mol} \mathrm{dm}^{-3}\right)$ both these substances stimulated the percentage of rooted cuttings, average number and length of adventitious roots. No marked inhibitory effect of PAA and IAA was exhibited even at the highest concentration, at which a toxical influence of NAA was apparent. On the contrary, they stimulated adventitious root formation in some species.

\section{Changes in the production of ethylene in leaves and ear of winter wheat (Triticum aestivum L.) during ontogenesis}

\author{
M. DUNDELOVÁ, V. REINÖHL, S. PROCHÁZKA and J. MIKULÍK \\ Institute of Botany and Plant Physiology, University of Agriculture, \\ Zemèdělská 1, 61300 Brno, Czechoslovakia
}

Biol. Plant. 34 (Suppl.): 574, 1992

The production of ethylene in leaves, stem and ear of the main stem of winter wheat cv. "Slavia" was estimated from the beginning of tillering to the period of full ripeness. We evaluated the ethylene production according to the relationship of the growth of leaf area, senescence of leaves, or formation of kernels. The increased ethylene production follows the growth of leaves. After reaching the maximum size of the leaf blade ethylene production decreases. The content of chlorophyll is decreased during senescence of leaves and at the same time the production of ethylene is decreased. During ontogenesis of the whole plants, two maxima in ethylene production were observed. The first maximum was observed in the period of the 8th Feekes phase (the 6th stage organogenesis), the second one at the end of flowering (11.5. Feeke's phase). In the period of kernel ripening the decreasing tendency of ethylene production was investigated.

\section{Regression forms of the mathematical modelling of plant growth}

\section{DVOŘÁK and J. ČERNOHORSKÁ \\ Department of Anatomy and Plant Physiology, Faculty of Science, Charles University, Viničná 5, 12844 Praha 2, Czechoslovakia}

Biol. Plant. 34 (Suppl.): 564-575, 1992

A method of non-linear regression is described, utilizing a choice of 12 functions, suitable for evaluation of processes (growth, nutrition uptake, development of assimilating surface, etc.) and situations (optimization of conditions for biomass production) in plant biology. Moreover, the method enables the experimenter interactive computer-checking to solve questions, created by the 
experiment. For this method we have constructed and for 10 years developed a very flexible software using Pascal:NlinRegr (for 16 bit, $I B M$ 'compatible computers with colour monitor, including supporting software, less then $300 \mathrm{kB}$ large), corresponding groups of data, which are permanently saved in external medium as two-dimension field, from where the program reads and processes them. System SIMPSON makes possible numerical derivative computation, calculation of RGR values, and evaluation of integrals according to regression functions or from data (suitable for cvaluation of assimilating surface and its productivity). In this way, NlinRegr creates an environment offering new appraisals of kinetics of the followed process according to external conditions. The method is good for evaluation of deduction correctness, deduced from experimental data. Output information could be in graphical or numerical form including statistical interpretation.

\title{
Production of ethylene and ethane from the cutting of Salix caprea $\mathbf{L}$.
}

\author{
H. FIŠEROVÁ* and V, PSOTA** \\ Institute of Botany and Plant Physiology, University of Agriculture, \\ Zemédelská 1, 61300 Bmo, Czechoslovakia* \\ Institute of Systematic and Ecological Biology, Czechoslovak Academy of Sciences, \\ Květná 8, 60365 Brno, Czechoslovakia**
}

Biol. Plant. 34 (Suppl.): 575, 1992

From the cuttings of willow Salix caprea $\mathrm{L}$. we have followed the reaction on exogenously added growth regulators of the type of auxinoids (indolyl-3-butyric acid - IBA) and cytokinins (4 PU 30derivative of diphenylurea N-phenyl-N-(2-chloro-4-pyridyl) urea) and DROPP (effective substance thidiazurone) on production of ethylene and ethane and forming roots and shoots. During one week of following IBA raised production of both gases and the average length of root statistically significantly, but it reduced the length of shoots. 4 PU 30 and DROPP cause higher levels of both hydrocarbons than control samples (the dependence of subrogation is coming near to conclusive evidence) but they do not form any roots and in comparison with the application of IBA they rise the number and length of shoots. Control samples produce low levels of ethylene and ethane without linear dependence of subrogation and form roots very easily.

\section{The effect of brassinosteroids on the growth} and endogenous phytohormone level in tobacco tissue cultures

\author{
A. GAUDINOVÁ, R. VAŇKOVÁ, M. KAMÍNEK and M. VOJTĚCHOVÁ \\ Institute of Experimental Botany, Czechoslovak Academy of Sciences, \\ Ke dvoru 15, 16630 Praha 6, Czechoslovakia
}

Biol. Plant. 34 (Suppl.): 575-576, 1992

Brassinosteroids seem to be, due to their high biological activity and low price, very promising xenobiotics with wide potential use in agriculture. The effect of two brassinosteroid derivatives (24epi and No. 4154) on the level of endogenous cytokinins and auxin has been tested in tissue cultures of Nicotiana tabacum L. cv. Wisconsin 38. The level of cytokinins was not remarkably affected by brassinosteroids present in cultivation media in the concentration range $10^{-9}-10^{-6} \mathrm{M}$. The content of ribosides (zeatin riboside and isopentenyladenosine) was only slightly decreased, the content of bases was not significantly affected. Brassinosteroid 24-epi when used in the same concentration range increased the level of endogenous auxin (indolylacetic acid) 2-4 times. These results indicate that previously published reports on the effect of brassinosteroids on the increase of tissue sensitivity towards the auxin may be, at least partially, explained by the increase of the endogenous auxin level. This conclusion has been further supported by the results of growth studies. 
Brassinosteroids applied into the cultivation media containing the level of exogenous auxin (naphthylacetic acid) optimal for growth did not exhibit significant effect on the growth of tobacco tissue cultures. However, when applied into the media with suboptimal level of auxin, the brassinosteroid considerably influenced the dynamics of the tissue growth. In this case the brassinosteroids probably stimulated the synthesis of the limiting auxin.

\title{
Rastim $30 \mathrm{DKV}$ - preparation for sugarbeet growth regulation, with relation to its yield and technological quality
}

\author{
M. HENSELOVÁ \\ Research Institute of Chemical Technology, 83603 Bratislava, Czechoslovakia
}

Biol. Plant. 34 (Suppl.): 576, 1992

Rastim $30 \mathrm{DKV}$ is an original plant growth regulator with a wide spectrum of biological effect. The effective substance is 3-(benzyloxycarbonyl-methyl)benzotiazoline-2-on. The final form is DKV, that means a liquid dispersable concentrate for dilution with water containing $300 \mathrm{~g} \mathrm{l}^{-1}$. It is an ecologically friendly preparation, with negative toxicological parameters, no risk of any unwanted residues. The preparation was applied in the cover of $1500 \mathrm{ml} \mathrm{l}^{-1}$ to sugarbeet and during the vegetation in the stage of $6-7$ couple leaves in $300 \mathrm{ml}$ and in the stage of the technological ripening of the plant 4-6 weeks before gathering in $180 \mathrm{ml}$ in the applied volume of $600-8001 \mathrm{ha}^{-1}$. The research of this preparation in practical conditions from 1985 till 1991 was realized in small plot trials in 20-50 $\mathrm{m}^{2}$ area in 4-6 repetitions and the pilot-plot experiments in 3-50 ha area. The preparation was evaluated with regard to the plant germination, field emergence rate, biomass formation yield, sucrose, ash contents $(\mathrm{Na}+\mathrm{K})$, and polarized sucrose and raphinades. The stimulated effects of the preparation on the field emergence rate occurred especially in the cultivations with the lower natural germination and prospering in deficient soil moisture conditions. The stimulation of the growth beginning of the plant after getting the preparation to the covering, as well as the vegetative growing after application to the leaves positively increased the yield and improved the technological quality of the plant. The application of the preparation to the cover has a positive effect on the increase of yield, which can be caused by better rooting and faster growing of the plant. The application to the leaves causes an increase in yield and sucrose, as well. The yield as well as sucrose content increase depends on the year, plant cultivation, region, nutrition, rainfall, etc. The better economical effectivity can be reached by divided applications. Todays research of this application is state registred and the research will be followed in CSFR conditions.

\section{Changes in the content of endogenous cytokinins after application of Rastim $30 \mathrm{DKV}$ preparation in sugarbeet (Beta vulgaris L.)}

\author{
M. HENSELOVÁ*, G. VIZÁROVÁ**, M. POHANKOVÁ* and V. KONEČNÝ* \\ Research Institute of Chemical Technology, 83603 Bratislava, Czechoslovakia* \\ Institute of Ecobiology, Slovak Academy of Sciences, 81434 Bratislava, Czechoslovakia**
}

Biol. Plant. 34 (Suppl.): 576-577, 1992

The content of endogenous cytokinins was determined in the leaves and roots of sugarbeet $\mathrm{cv}$. Intera after the application of Rastim $30 \mathrm{DKV}$ preparation. The effective substance of the preparation is benzolinon, chemically 3-(benzyloxycarbonyl-methyl)benzothiazolin-2-on. The preparation was applied in two phenophases of growing, in the stage of $6-7$ couple true leaves in $300 \mathrm{ml}$ ratio, and in the phase of the technological ripening, that means 5 weeks before harvest in $180 \mathrm{ml}$ ratio in $600 \mathrm{l}$ of the applied volume ha-1. The biological matter (root and top) was taken in one week and one month intervals and fixed in $80 \%$ ethylalcohol. After the extraction of cytokinin, their 
biological activity was determined by Vizárova and Vozár (1984) method. The analyses of the endogenous cytokinins in the root and top of the sugarbeet after the application of the preparation showed the increased content of this preparation in comparison, mostly in the root, but in contrast with this result, no big changes in the top were found. The increased content of cytokinins, which was preserved from the time of application till the gathering, which correlated with the positive influence of the yield, which was increased in the average by about $10 \%$ and the sucrose content by ahout $5 \%$. We guess, that through the increased activity of the endogenous cytokinins is realized the biological effect of the preparation, as well. The increased content of sucrose can be the result of the increased glucoside for cytokinin content, that is zeatin glucoside, which correlates with the results of Brúhova et al. (1987). The detailed description of the functions and the relation of endogeouns cytokinins to the yield and sugarbeet's quality will be evident in the following analysis of biological material straight from field conditions, and the continuation in metabolic and hormone research, planned in 1992.

References:

Vizárová, G., Vozár, I.: Biochem. Physiol. Pflanz. 179: 767, 1984.

Brúhová, A. et al.: Biológia (Bratislava) 42: 33, 1987.

\title{
Synthetic regulators and correlations in pea seedlings
}

\author{
J. HRADILÍK and H. FIŠEROVÁ \\ Institute of Botany and Plant Physiology, University of Agriculture, \\ Zemédëlská 1, 61300 Brmo, Czechoslovakia
}

Biol. Plant. 34 (Suppl.): 577, 1992

Synthetic stimulators (GIBERSIB, STILIT-12, KREZACIN, TITAVIN, KROTONOLAKTON, INDOFOR and AZOXOFOR), which have already been manufactured, were locally applied to model pea seedlings. AZOXOFOR: promoted root elongation growth markedly in decapitated plants while slightly stimulated the growth of epicotyl in intact plants. It did not influence correlation between the cotyledon and its axillary bud. KROTONOLAKTON: if applied to the cotyledon of decapitated plant it often stimulated the growth of the opposite cotylar. TITAVIN: if applied to the rest of the reduced cotyledon of decapitated plant it was often responsible for correlative reversal and induction of the cotylar growth in the axilla of the remaining cotyledon. STILIT-I2: partially retarded root elongation in intact plants. GIBERSIB: stimulated the elongation growth of epicotyl in intact plant and promoted the growth of cotylar in the axilla of the treated cotyledon. If applied to the rest of the cotyledon it stimulated the growth of the opposite cotylar by $40 \%$, and thus was responsible for correlative reversal. INDOFOR and KREZACIN: had no influence on the growth of pea seedlings.

\section{The influence of some growth regulators on the ethylene production in pea (Pisum sativum L.)}

\section{J. HRADILÍK, V. REINÖHL and V. PLŠEK}

Department of Botany and Plant Physiology, University of Agriculture, Zemèdelská I. 61300 Brno, Czechoslovakia

Biol. Plant. 34 (Suppl.): 577-578, 1992

The ethylene production was measured in 4-d old etiolated pea seedlings: intact, decapitated and decapitated with one cotyledon excised. The mean ethylene production of intact control plants was $0.18 \mathrm{nl} \mathrm{h}^{-1} \mathrm{~g}^{-1}$ (fresh mass), decapitated $0.13 \mathrm{nl} \mathrm{h}^{-1} \mathrm{~g}^{-1}$ (fresh mass). The growth regulators were applied in agar blocks on the epicotyl hook, epicotyl stump and on cut surface after the cotyledon 
excision. A significant induction of ethylene production (5 - 25x) was caused by indolyl-3 acetic acid (conc. 0.1 and $0.5 \%$ in agar) in all three kinds of application. Benzyladenine $(0.1$ and $0.5 \%$ ) applied on intact plants slightly diminished the ethylene production $(1.2-1.3 x)$ and applied on decapitated plants the production increased $(1.5-2 x)$. Abscisic acid and paclobutrazol (commercial product Cultar) applied on the epicotyl stump and the cut surface after the cotyledon excision increased the ethylene production $(1.2-2.7 \times)$.

\title{
Correlations between plant organs during the processes of ripening and senescence
}

\section{Z. JUREKOVÁ and M. MLADÝ}

Department of Plant Physiology, University of Agriculture, A. Hlinku 2, 94976 Nitra, Czechoslovakia

Biol. Plant. 34 (Suppl.): 578, 1992

The interest about the study of physiology of the ripening and senescence from view of importance of these processes for plant ontogenesis programme realization is increasing. From this point of view the correlation between plant organs and also the conditions which influence the concurrent hormonal changes were investigated. We followed the period of cereal leaves activity and the changes in the relationship between plant organs during senescence. These are determinated by both individual organ ontogenesis and ontogenesis of the whole plant. The noted problems were investigated using intact plants and isolated leaves during senescence and regeneration under different condition (irradiation, temperature, etc.). During the processes of senescence and rejuvenation both the endogenous gibberellin and ethylene were determined.

\section{The effects of aromatic cytokinins (populins) on micropropagation and regeneration of sugar beet in vitro}

\author{
M. KUBALÁKOVÁ and M. STRNAD \\ Institute of Experimental Botany, Czechoslovak Academy of Sciences, \\ Sokolovská 6, 772 00 Olomouc, Czechoslovakia
}

Biol. Plant. 34 (Suppl.): 578-579, 1992

The effects of aromatic and isoprenoid cytokinins on micropropagation and organogenesis of sugar beet cultured in vitro were studied. A diploid CMS sugar beet linie No. 22003 (supplied by Breeding Station Kralice na Hané) was used. The primary culture was derived in 1985 from axillary buds. Shoot tips propagated 1 month on MS medium without growth regulators were used as explants. The following cytokinins were tested in these experiments: $\mathrm{N}^{6}$-benzylaminopurine (BAP), trans-zeatin (Z), ortho-(oP) and meta-populin (mP) applied in three different concentrations $-1 \mu \mathrm{M}$, $S \mu \mathrm{M}$ and $10 \mu \mathrm{M}$. In each variant 15 explants in 3 replicates were established. High frequency of new shoot formation was observed on medium containing meta-populin (number of shoots per explant after 4 weeks was 5.4). BAP exhibited lower activity in micropropagation (4.1 shoots). Both $\mathrm{oP}$ and $\mathrm{Z}$ were (almost 2 times) less active than $\mathrm{mP}$ (3.6 and 3.1). The negative effects of higher BAP concentration on shoot development (leaf and petiole shortening, malformation) was observed after several transferring on the same medium. The root formation was inhibited. Neither populin exhibited the negative effects of high concentration. Aromatic cytokinins were also used for induction of regeneration from sugar beet petioles. High regeneration was observed after application of $\mathrm{mP}$ and $\mathrm{BAP}$. Medium containing $\mathrm{OP}$ and $\mathrm{Z}$ did not induce a shoot proliferation. Results 
presented here indicate that populins might be a new source of cytokinins with high morphogenetic activity. Their practical importance for in vitro manipulation is further studied.

\title{
Exact calculation of the daylength
}

\author{
M. LIGR*, C. RON** and L. NÁTR* \\ Department of Plant Anatomy and Physiology, Charles University, \\ Viničná 5, 12844 Praha 2, Czechoslovakia ${ }^{*}$ \\ Astronomical Institute, Czechoslovak Academy of Sciences, \\ Budečská 6, 12023 Praha 2, Czechoslovakia**
}

Biol. Plant. 34 (Suppl.): 579, 1992

The possibility to simply and exactly calculate the length of the day for different localities is essential not only for the models describing photoperiodical effects of the light on the plant development but also for the simulation of the daily sum of the produced photosynthates or the calculation of the average daily temperature. Two simple algorithms for calculation of photoperiod length (K-algorithm: Keisling 1989 and W-algorithm: Weir, A.H. et al., 1984) were compared with our one based on the equations system for describing the Earth movement around the Sun. The data obtained by the $\mathrm{K}$ - and $\mathrm{W}$-algorithms did not differ significantly. The curve gained by our algorithm is asymmetrical with respect to daylength in equinoxes, while the curve showing the data calculated by $\mathrm{K}$ - and $\mathrm{W}$-algorithm is apparently symmetrical. The higher the value of latitude degree, the higher differences between data calculated by compared algorithms. The values of the daylength calculated by our and $\mathrm{K}$ - and W-algorithms differ in $50^{\circ} \mathrm{N}$ maximally by $8.7 \mathrm{~min}$. The differences decline to the negligible value if in $\mathrm{K}$ - and $\mathrm{W}$-algorithms the refraction is used. The differences between values of the phylochron calculated according to 3 compared algorithms are negligible. Effect of the location height above field level on the photoperiod length is significant only when its values are in order of $1000 \mathrm{~m}$ (at this height the extension of photoperiod length is $5.2 \mathrm{~min}$ in $50^{\circ} \mathrm{N}$ ). The effect of sun angle below horizon was also tested. The decline of the Sun by $16^{\prime}$ causes prolongation of the photoperiod in $50^{\circ} \mathrm{N}$ to $4.2 \mathrm{~min}$. Daylength is linearly dependent on the Sun angle below horizon. It was demonstrated that the length of a particular day is different each year when calculated by our program, because influence of planet gravitation forces is considered.

References:

Keisling, T.C.: Agron. J. 74: 758-759, 1989

Weir, A.H. et al.: J. agr. Sci. 102: 371-382, 1984

\section{Inhibitory effect of direct electric current on flowering and its employment in studies of rhythmicity of flowering in Chenopodium rubrum}

\author{
1. MACHÁČKOVÁ and J. KREKULE \\ Institute of Experimental Botany, Czechoslovak Academy of Sciences, \\ Ke dvoru 15, 16630 Praha 6, Czechoslovakia
}

Biol. Plant. 34 (Suppl.): 579-580, 1992

Direct electric current (DC) of low intensity $\left(6 \mu \mathrm{A}_{\text {plant }}{ }^{-1}\right)$ inhibits photoperiodic flower induction in the short-day plant Chenopodium rubrum under following conditions: $I$ ) DC is applied for at least $2 \mathrm{~h}$ during the inductive darkness or $4-6 \mathrm{~h}$ of subsequent light and $a$ ) cathode is connected with the above-ground part, anode with the roots or $\mathrm{b}$ ) cathode is connected with such a part of the shoot, which belongs to the transpon way from leaves to apex. These observations suggest that applied DC interferes with the transport of "floral stimulus" from leaves to apex. DC changes the fluxes of 
cations $\left({ }^{45} \mathrm{Ca}^{2+}\right)$ and anions $\left({ }^{32} \mathrm{Pi},{ }^{36} \mathrm{Cl}\right)$. Both are more intensively moving to the cathode and some changes in the distribution of these ions in the stem were observed. DC has no effect on flux and distribution of sucrose. Chenopodium rubrum reveals in constant darkness an endogenous rhythm of flowering with maxima in the 13th and the 44th $\mathrm{h}$ of darkness. DC applied during the 4 last $\mathrm{h}$ of darkness in studies of endogenous thythm cancelled fully the first peak of flowering after $13 \mathrm{~h}$ of darkness. Around the 16th $\mathrm{h}$ of darkness DC starts to lose its efficiency and its effect on the second peak of flowering is very low. This means that if our explanation of inhibitory effect of $D C$ by interference with "floral stimulus" transport were correct, then there is no need of such a transport for the second peak of flowering. In such a case, once the apex received the stimulus, it is "evoked" and there is some rhythmicity in realization of this evoked state. To study the possible rhythmicity residing in the apex we treated the plants with DC for $4 \mathrm{~h}$ successively during $44 \mathrm{~h}$ of darkness and transferred them all at once to light at the time of the second peak of flowering. In this case fluctuations in flowering and apex height appeared, which bear the pattern of the $20 \mathrm{~h}$ thythm described by King (1975). Thus, we consider changes in apex sensitivity to the stimulus the most probable explanation of endogenous rhythmicity of flowering in $C$. rubrum.

\title{
Reference:
}

King, R.W.: Amer. J. Bot. 53: 2631, 1975.

\section{Changes in cytokinin level and distribution during photoperiodic flower induction in Chenopodium species}

\author{
I. MACHÁČKOVÁ, J. KREKULE and J. EDER \\ Institute of Experimental Botany, Czechoslovak Academy of Sciences, \\ Ke dvoru 15, 16630 Praha 6, Czechoslovakia
}

Biol. Plant. 34 (Suppl.): 580, 1992

Level of free cytokinins (zeatin, zeatin riboside, isopentenyladenine, isopentenyladenosine) decrease during the dark phase of the inductive cycle consisting of $12 \mathrm{~h}$ darkness, $12 \mathrm{~h}$ light in leaves, stems and roots of short-day plant Chenopodium rubrum. Cytokinin levels increased again during the light phase reaching at the end of the inductive cycle a value similar to that at its beginning. In apical parts, an opposite trend was observed: increase in cytokinin levels at the end of the light phase. Similar changes, i.e. decrease in darkness and increase in light in leaves, stems and roots were found also in long-day Chenopodium murale, where this photoperiodic regime keeps plants vegetative. In both $C$. rubrum and $C$. murale, no changes in cytokinin levels were found under continuous light; the exception were apical parts of $C$. murale, where a steady increase af cytokinin levels was found during $10 \mathrm{~d}$ of continuous light, which induce flowering in this plant. The decrease in darkness of cytokinin levels in leaves of $C$. rubrum is not fully reverted by night-break $(15 \mathrm{~min}$ red $/ R /$ in the 6th hour of darkness), which prevents flowering. On the other hand, the increase of cytokinin levels in the apical parts of $C$. rubrum was almost fully inhibited by night-break, the effect of which was not reverted by far red ( $30 \mathrm{~min}$ immediately after $R$ ), which prevents the R-break inhibitory effect on flowering. A dark period of $12 \mathrm{~h}$ changes in $\mathrm{C}$. rubrum plants the distribution of labelled ${ }^{3} \mathrm{H}$ isopentenyladenine and ${ }^{3} \mathrm{H}$-zeatin administred via roots at the beginning of darkness. There is a decrease of radioactivity in leaves and increase in apical parts in comparison with plants from constant light. Night-break effectively prevents the described effect of darkness on distribution. Also, the amount of cytokinins in xylem exudate changes due to photoperiod. Darkness increases ZR level in xylem sap. Thus we assume that unlike the fluctuations of cytokinin levels in leaves, stems and roots, which seem to merely reflect photoperiodic conditions, those in the apical parts might be linked with developmental status. 


\title{
Leaf plasmalemma from Chenopodium rubrum during photoperiodic induction of flowering
}

\author{
J. MARTINEC*, P. CRESPI**, M. CREVECOEUR** and H. GREPPIN** \\ Institute of Experimental Botany, Czechoslovak Academy of Sciences, \\ Ke dvoru 15, 16630 Praha 6, Czechoslovakia* \\ Laboratory of Plant Physiology, University of Geneva, \\ 3 place de l'Université, 1211 Geneva 4, Switzerland**
}

Biol. Plant. 34 (Suppl.): 581, 1992

Structural changes of plasmalemma could play an important role in photoperiodic induction of flowering. The plasma membrane was isolated by aqueous dextran-polyethyleneglycol two-phase partitioning from leaves of the short day plant Chenopodium rubrum. Purity of plasmalemma was determined on the basis of both activity of the enzyme markers $\left(\mathrm{K}^{+}, \mathrm{Mg}^{2+}\right.$ ATPase, $1,3-\beta$-glucan synthase II, cytochrome $c$ oxidase, cytochrome $c$ reductase, latent IDPase) and membrane morphology. The thickness of plasmalemma of induced and vegetative plants was measured. It was found that thickness of plasmalemma was higher in induced plants. Total plasmalemma lipids were extracted and sterol content was quantified during photoperiodic induction by reverse phase high performance liquid chromatography. These experiments showed a rapid $(4 \mathrm{~h})$ increase of plasma membrane sterol content during induction. Results are discussed in relation to similar analyses runned in spinach (Spinacia oleracea), the long-day plant.

\section{The effect of exogenous cytokinins in the culture medium on cytokinin oxidase activity in soybean callus tissue}

\author{
V. MOTYKA and M. KAMÍNEK \\ Institute of Experimental Botany, Czechoslovak Academy of Sciences, \\ Ke dvoru 15, 16630 Praha 6. Czechoslovakia
}

Biol. Plant. 34 (Suppl.): 581-582, 1992

Degradation of cytokinins in plant tissues is governed by the specific enzyme, cytokinin oxidase. This enzyme was extracted and partially purified from soybean (Glycine max (L.) Merr. cv. Altona) callus grown on the medium containing auxin $\left(5.310^{-6} \mathrm{M} \mathrm{NAA}\right)$ and various cytokinins in a wide range of concentrations $\left[10^{-9}-10^{-5} \mathrm{M}\right.$ trans-zeatin, dihydrozeatin, BAP and $\mathrm{N}^{6}$-(m-hydroxybenzyl)adenosine]. A significant increase in cytokinin oxidase activity was detected in cultures grown on media with a high cytokinin content $\left(10^{-5} \mathrm{M}\right)$. The enzyme activity was $2 \cdot 15$ fold higher than that of control tissue grown on cytokinin-free medium. The activity of the enzyme from calli grown on media with lower cytokinin concentration $\left(10^{-9}-10^{-6} \mathrm{M}\right)$ did not exceed that of control. Both substrate (trans-zeatin) and non-substrate (dihydrozeatin, BAP, $\mathrm{N}^{6}$-(m-hydroxy-benzyl)adenosine) cytokinins were active in the regulation of cytokinin oxidase activity in this way. The regulatory effect was not genotype-specific and was observed also in other soybean cultivars (Sluna, Polanka). These results suggest that cytokinins exogenously applied to culture media in high concentration may actually induce cytokinin oxidase, this destroying an internal pool of endogenous "biologically active" cytokinins. This effect is in accordance with the regulation of cytokinin oxidase activity by surface-application of cytokinins to the calli of some other plants species (Chatfield and Armstrong 1986, Kamínek and Armstrong 1990, Motyka and Kaminek 1992). This may also be a possible explanation for the failure of exogenous cytokinirs to stimulate cell division and bud initiation in some plant tissue cultures.

\section{Reference:}

Chatfield, J.M., Armstrong, D.J.: Plant Physiol. 80: 493, 1986. 
Kamínek, M., Armstrong, D.J.: Plant Physiol. 93: 1530, 1990.

Motyka, V., Kamínek, M.: In: Kamínek, M., Mok, D.W.S., Zažímalová, E. (ed.): Physiology and Biochemistry of Cytokinins in Plants. Pp. 33-39. SPB Acad. Publ., The Hague 1992.

\title{
The key enzymes of glutamine metabolism in the second wheat leaf ontogeny
}

\section{NOVOTNÁ}

Department of Plant Anatomy and Physiology, Charles University, Vinična 5, 12844 Praha 2, Czechoslovakia

Biol. Plant. 34 (Suppl.): 582, 1992

Changes of activities and isozymes spectra of glutamine synthetase (GS, E.C. 6.3.1.2.) and glutamate dehydrogenase (GDH, E.C. 1.4.1.2. - 4.) during the ageing of the second wheat leaf (Triticum aestivum L., cv. Grana) were measured. Plants were grown in a full-strength Knop's nutrient solution (FS), and in a nutrient solution from which nitrogen was omitted (-N) for inducing senescence. The activity of glutamine synthetase increased from $5 \mathrm{~d}$ to $17 \mathrm{~d}$, where the peak occurted. Thereafter, the activity slowly decreased. Similar trend in the $-\mathrm{N}$ variant was observed. GS activity was the highest in the mature, fully expanded second leaf, and the results indicate an important regulatory role of photosynthetic pathways as an energetic supply. Banding patterns of glutamine synthetase were compared following polyacrylamide gel electrophoresis. From $5 \mathrm{~d}$ to $12 \mathrm{~d}$ plant age two GS isozymes were observed (GS I and GS II), however, GS I only in the immanure parts of leaf. Only a single GS isozyme (GS II) was detected in extracts of green mature leaves. The peak of GDH activity in the reductive amination of 2-oxoglutarate between $12 \mathrm{~d}$ and $17 \mathrm{~d}$ was observed., however, in both experimental variants before finishing leaf development. Then the activity of reductive amination strongly declined. The activity of GSH in the oxidative deamination of glutamate in senescing leaf tissue significantly increased. In extract of leaves two GSH isozymes were found. The bands with glutamate dehydrogenase activity by $R_{f}=0.15$ and 0.24 were characterized.

\section{A study of dormancy in lilac (Syringa vulgaris L.) buds}

\author{
M. OPLUŠTLOVÁ \\ Institute of Systematic and Ecological Biology, Czechoslovak Academy of Sciences, \\ Kvètná 8, 60365 Brmo, Czechoslovakia
}

Biol. Plant. 34 (Suppl.): 582, 1992

The dormancy of lilac (Syringa vulgaris L.) buds was studied using experimental morphological methods. A deep bud dormancy of intact annual shoots was broken by shoot segmentation when the basal buds terminated dormancy earlier than those from the apical part of the shoot. Growth regulators, i.e. $\mathrm{GA}_{3} 20 \mathrm{mg} \mathrm{dm}^{-3}$ and $\mathrm{BA} 1 \mathrm{mg} \mathrm{dm}^{-3}$, explicitly retarded the bud growth from the basal part of the shoot in the post-dormant period. Application of ABA $10 \mathrm{mg} \mathrm{dm}^{-3}$ to post-dormant buds did not prevent their bursting but caused their consequent withering. Provided that ABA was applied as a solution in which the annual shoots were cultivated in summer the solution of $A B A$ $20 \mathrm{mg} \mathrm{dm}^{-3}$ was responsible for inhibition of their growth. 


\title{
The effect of gallic acid on tyrosinase activity
}

\author{
F. POSPIŚIL \\ Institute of Experimental Botany, Czechoslovak Academy of Sciences, \\ Na Karlovce 1, 16000 Praha 6, Czechoslovakia
}

Biol. Plant. 34 (Suppl.): 583, 1992

Phenolic acids have a heterogenous effect on enzyme activity. The magnitude and nature of the effect is related to the chemical structure and concentration of the phenolic acid. The effect of gallic acid and gallic acid oxidation product on tyrosinase activity is reported here. Sources of the enzyme were the potato tuber slices and pure tyrosinase from mushroom (Sigma). Tyrosinase activity was determined by an electrochemical method on a rotating disk glassy-carbon or platinum electrode. Voltammetric and polarographic data were obtained using a PA 4 Polarographic Analyzer. Catechol was oxidized in the presence of hydroquinone as mediator, the o-quinone formed by enzymatic oxidation is then quantitatively reduced back to catechol, the $p$-benzoquinone generated in this latter reaction can readily be determined on a rotating electrode at $-0.050 \mathrm{~V}(\mathrm{vs}$. Ag-AgCl). At pH 6.5 gallic acid at a concentration of $5 \mu \mathrm{g} \mathrm{cm}^{-3}$ inhibited enzyme activity by $24 \%$ and this inhibition increased with time by $60 \% \mathrm{~h}^{-1}$. The inhibition of mushroom tyrosinase activity by gallic acid at a concentration of $35 \mu \mathrm{g} \mathrm{cm}^{-3}$ was by $85 \%$. Gallic acid was preincubated with enzyme for $20 \mathrm{~min}$. Different coloured products are involved in the oxidation of gallic acid by tyrosinase. The resulting quinones were reduced at a dropping mercury electrode at -0.5 and $-1.0 \mathrm{~V}(v \mathrm{~s}$. SCE) and two waves were observed. 3-hydroxy-1,2-benzoquinonecarbonic acid and finally purpurogallic acid were probably formed. Gallic acid oxidation product at a concentration of $83 \mu \mathrm{g} \mathrm{cm}^{-3}$, preincubated with enzyme for $20 \mathrm{~min}$ inhibited nushroom tyrosinase activity by $60 \%$. Oxidation products were reduced at a dropping mercury electrode in phosphate buffer at pH 6.5 at $-0.9 \mathrm{~V}$ (vs. SCE). Kinetic studies showed that gallic acid and gallic acid oxidation product can influence the enzyme activity rather than interacting primarily with catechol. We suggest that such inhibition is due to the irreversible binding of the enzyme to the gallic acid oxidation products, by the blocking of the active sites of the enzyme.

\section{Transport of plant growth substances and growth correlations in flax seedlings (Linum usitatissimum)}

\author{
S. PROCHÁZKA* , B. BORKOVEC**, M.E.-D. IBRAHIM* and J. BLAŽKOVÁ* \\ Department of Botany, University of Agriculture, Zemédělská 1,613 00 Brno, Czechoslovakia* \\ Department of Nuclear Methods, University of Agriculture, \\ Zemédèlská I, 61300 Brno, Czechoslovakia**
}

Biol. Plant. 34 (Suppl.): 583, 1992

After decapitation of the apex, the apigeic cotyledon stimulated the growth of its bud. The cytokinin-like substances are transported from roots to the growing buds as well as to the inhibited buds, at the same time increasing their fresh mass. Transport of abscisic acid into inhibited buds is more intensive when applied to the cotyledons. Abscisic acid stimulated the transport of sucrose to the growing buds. There is a close connection between the substances synthetized and transported from epigeic cotyledons (sucrose, cytokinins, $\mathrm{ABA}$ ) and substances synthetized and transported from the roots (ABA, cytokinins) under growth correlations between the epigeic cotyledons and cotyledonary buds. 


\title{
Auxin and ethylene during adventitious root formation
}

\author{
V. PSOTA*, H. FIŠEROVÁ** and B. LÁNÍČKOVÁ* \\ Institute of Systematic and Ecological Biology, Czechoslovak Academy of Sciences, \\ Kvétmá 8, 60365 Brmo, Czechoslovakia* \\ Department of Botany and Plant Physiology, University of Agriculture, \\ Zemědélská 1, 613 00 Brmo, Czechoslovakia**
}

Biol. Plant. 34 (Suppl.): 584, 1992

During adventitious root formation of Salix babylonica L. stem cuttings taken in March 1992, the level of $\beta$-indoleacetic acid (IAA) and ethylene production were investigated using the $\alpha$-pyrone method and gas chromatography, respectively. The highest level of endogenous IAA was recorded $24 \mathrm{~h}$ after cutting excision followed by a decrease. Prior to proliferation of adventitious roots the IAA level reached the lowest value. After the application of phenylacetic acid (PAA) no change was found in the content of endogenous IAA. The cuttings responded to PAA application by an increase in ethylene production. In cuttings treated with PAA two maxima of ethylene production were recorded. The first after PAA application and the second one, conformably with controls, prior to proliferation of adventitious roots.

\section{Correlations in forest trees}

L. RAUSCHEROVÁ and J. KRÁLÍK

Institute of Systematic and Ecological Biology, Czechoslovak Academy of Sciences, Květná 8, 60365 Bmo, Czechoslovakia

Biol. Plant. 34 (Suppl.): 584, 1992

The paper summarizes evaluation of growth-correlative effects of epigeic and hypogeic cotyledons in selected tree species. In decapitated seedlings, the stimulatory or inhibitory influence of the remaining cotyledon on the growth of axillar bud was evaluated mathematically. In the remaining and amputated cotyledons, the growth of the cotylar was tested using the method of chi square on the basis of the null hypothesis, and compared with model plants. According to this evaluation, cotyledons of some tree species behaved as typically hypogeic (Juglans regia), others exhibited a stimulative effect characteristic for epigeic cotyledons (Acer pseudoplatanus). The other species under investigation deviated from both the boundary types. In some tree species, the response to exogenous application of growth regulators was observed. Likewise at this point, the results showed differences in the response according to the species.

\section{Substance stimulating starch accumulation in pith explants of kale and endogenous cytokinins}

\author{
V. ŘEẺ̉ÁBEK, A. HÁJEK and J. LUŠTINEC \\ Institute of Molecular Biology, Czechoslovak Academy of Sciences, \\ Branišovská 31, 37005 Ceské Budéjovice, Czechoslovakia
}

Biol. Plant. 34 (Suppl.): 584-585, 1992

If stem explants of kale (Brassica oleracea L. var. medullosa) containing pith parenchyma and a strip of vascular tissue are cultured on simple sucrose medium, a substance is transported from the vascular tissue to the pith, where it stimulates accumulation of starch. Similarly, up to ten fold increase of starch content in explanted parenchyma can be induced by cytokinins (native or 
synthetic) added to culture medium. Using immunoanalysis (ELISA) the concentrations of endogenous cytokinins trans-zeatin, isopentenyladenine and their ribosides were determined in explants. Concentrations of total cytokinins were determined using Amaranthus bioassay. No effect of vascular tissue on endogenous cytokinin level in explants was found.

\title{
The growth correlating effect of sunflower roots in terms of IAA and GA
}

\author{
K. SLABÝ*, J. ŚEBÁNEK* and V. PSOTA** \\ Department of Botany and Plant Physiology, University of Agriculture, \\ Temédélská 1, 61300 Brno, Czechoslovakia* \\ Institute of Systematic and Ecological Biology, Czechoslovak Academy of Sciences, \\ Pořicí 3b, 60300 Brno, Czechoslovakia**
}

Biol. Plant. 34 (Suppl.): 585, 1992

The roots of sunflower seedlings grown in darkness stimulate shoot growth, so that within $24 \mathrm{~h}$ after the excision of the root the growth of the hypocotyls is inhibited. In 5-d-old plants, this inhibition is associated with a reduced activity of endogenous gibberellin-like substances in the cotyledons and hypocotyls. On the other hand, gibberellin activity in the roots increases after the excision of the shoot. Within $24 \mathrm{~h}$ the content of IAA in the hypocotyls of plants deprived of roots is higher than in the hypocotyls of intact plants. However, there is no significant difference in the level of IAA in the roots between the two variants. The inibiting effect of IAA on the growth of hypocotyls was found after placing the plant seedlings into an IAA solution of a concentration of $0.1 \mathrm{mg} \mathrm{l}^{-1}$. The inhibition was stronger in intact plants than in the plants where the root was removed. On the other hand, $\mathrm{GA}_{3}$ solutions of concentrations of 10 and $100 \mathrm{mg} \mathrm{l}^{-1}$ had a stronger stimulating effect on plants deprived of roots than on intact plants. In addition, the determination of the activity of gibberellins in apical sections of hypocotyls showed that this activity was higher in experimental plants without roots than in intact plants. From the results it follows that in this correlation it is possible to substitute the stimulating effect of the root with exogenous gibberellin.

\section{Discovery of new cytokinin family}

\section{STRNAD \\ Institute of Experimental Botany, Czechoslovak Academy of Sciences, Sokolovská 6, 77200 Olomouc, Czechoslovakia}

Biol. Plant. 34 (Suppl.): 585-586, 1992

An attempt to understand the regulatory role of cytokinins in plants led us to the speculations that aromatic cytokinins might act as important growth-regulating substances. For verification of this hypothesis we prepared a partially purified methanolic extract of mature poplar leaves (Populus $\times$ canadensis Moench cv. Robusta) which was subjected to successive chromatographic purification steps on cellulose phosphate, on combined $D E A E$ cellulose-reversed phase columns and by high performance liquid chromatography (HPLC) on Separon SGX $C_{18}$. Presence of the unknown immunoreactive compounds in HPLC fractionated extract was located by enzyme-linked immunosorbent assays (ELISA) for $\mathbf{N}^{6}$-benzylaminopurine riboside (BAPR) and its ortho- or metahydroxylated derivatives ( $O P R, \mathrm{mPR}$ ). The antibodies of molecular recognition properties specifically directed to a particular structure of BAP, $\mathrm{mP}$ and/or oP have been used in ELISA. Hence, in addition to the free base, the other 9-substituted derivatives (e.g. ribosides, ribotides, 9-glucosides or amino acid conjugates) cross-react with these antibodies and thus can be measured by immunoassay if present in the same fraction. To establish completely the identity of the unknown compounds, the appropriate immunoreactive fractions were converted into their 
trimethylsilylated derivatives and/or permethyl esters, which were subsequently purified by HPLC and examined by gas chromatography-mass spectrometry (GC-MS). Three different group of aromatic cytokinins have been identified. These compounds were named $\mathbf{N}^{6}-(2-$ hydroxybenzylamino)purine or ortho-populin and $\mathrm{N}^{6}$-(3-hydroxybenzylamino)purine or metapopulin. The third group of aromatic cytokinins consists of $\mathrm{N}^{6}$-benzylaminopurine metabolites. $\mathrm{mP}$ and $\mathrm{MPR}$ are as highly active as trans-zeatin in many cytokinin bioassays and exhibit high morphogenetic potential in different plant tissue cultures.

\title{
Qualitative properties of Anthemis tinctoria L. with respect to the main phases of ontogenesis
}

\section{S. VAVERKOVÁ, M. MRLIANOVÁ and B. BLANÁRIK \\ Department of Farmacognosy and Botany, Faculty of Pharmacy, Odbojárov 10,832 32 Bratislava, Czechoslovakia}

Biol. Plant. 34 (Suppl.): 586, 1992

Anthemis tinctoria $\mathrm{L}$. is a perennial herb of $30-60 \mathrm{~cm}$ height, used in natural medicine due to its hepatoprotective effect. The object of the present study were floral artires the quality of which was evaluated on the basis of their flavonoids content during the whole ontogenesis period of floral organs. Two species of the above mentioned herb were investigated; as to the amounts of active ingredients the most interesting showed to be the phase with floral attire containing two thirds of tubular flower buds.

\section{Cytogenetic changes and morphogenic capacity of Hypericum perforatum L. seedlings after cryostorage of seeds}

\author{
E. VRANOVÁ, E. ČELLÁROVÁ and R. BRUTOVSKÁ \\ Department of Experimental Botany and Genetics, Faculty of Science, P.J. Safarik University, \\ Mánesova 23, 04154 Kosice, Czechoslovakia
}

Biol. Plant. 34 (Suppl.): 586, 1992

Storage of seeds in liquid nitrogen $\left(-196^{\circ} \mathrm{C}\right)$ offers the following potential advantages over more conventional methods: 1 . absence of complicated temperature and humidity controls, 2 . freedom from damage by pests and diseases, 3. indefinite life span with little or no genetic change (Styles $e$ t al. 1982). The influence of freezing stress on germination of seeds, morphogenesis of explants and genetic stability of Hypericum perforatum L. cv. Topas has been studied. Because of low water content $(5-6 \%)$, the seeds of Hypericum perforatum were immersed directly in the liquid nitrogen and stored. The seeds were taken out after $5 \mathrm{~d}$ and thawed at laboratory temperature. The germination test was carried out on wet filter paper in Petri dishes under controlled culture conditions. No significant differences in germination rate were found between the frozen and control samples. $13 \%$ of root tips of seedlings had altered somatic chromosome number, which normally is $2 n=4 x=32$. We observed the euploid multiplications of basic chromosome number $(2 n=16,24$, $40,48,64)$. The alterations were not significant in comparison with seedlings germinated from unfrozen seeds. The morphogenic capacity was studied after inoculating of seedlings on the induction medium supplemented with 6-benzylaminopurine within the concentration range of 0.44 to $4.40 \mu \mathrm{M}$. Cryostorage of seeds positively affected morphogenic capacity of seedlings. Numbers of regenerated shoots per seedling explant were higher than those of the controls.

Reference:

Styles, E.D., Burgess, J.M., Mason, C., Huber, B.M.: Cryobiology 19: 195-199, 1982. 
Effect of exogenous application of benzylaminopurine on elongation growth and content of chlorophylls in young barley plants (Hordeum vulgare cv. Perún) influenced by aluminium-stress in pH 6.5 and 4.5

\section{T. ZATKALÍKOVÅ}

Institute of Ecohiology, Slovak Academy of Sciences, Mlynské Nivy 59, 81434 Bratislava. Czechoslovakia

Biol. Plant. 34 (Suppl.): 587, 1992

The effect of benzylaminopurine (BAP) on growth and chlorophyll content in young barley plants was investigated. The plants grown in nutrient solutions with low concentration of $\mathrm{Al}^{3+}\left(\mathrm{Al}_{2} \mathrm{SO}_{4}\right)_{3}$ $18 \mathrm{H}_{2} \mathrm{O}-10^{-8} \mathrm{M}$ ) at $\mathrm{pH} 6.5$ and 4.5. $10^{-5} \mathrm{M}$ BAP was applied on shoots. For application 9-d-old seedlings of barley were used. BAP stimulated elongation of shoots after $3 \mathrm{~d}$ of application. The content of chlorophyll $a$ was decreased at $\mathrm{pH} 6.5$, the content of chlorophyll $b$ was decreased at both values of $\mathrm{pH}$. 